\title{
Internet in Rural Communities
}

\author{
Jennifer Schnier, Ec.D.
}

Honey Harbour in the Township of Georgian Bay has been identified by the Muskoka Growth Strategy as the number one community in Muskoka for residential growth. As a waterfront community with limited ability to expand geographically, the community looked to the Internet for sustainable economic development options. The question being: 'if the Internet was available for the travelling public, would the travelling public use it, how would they use it, and what would it mean for the community?'

Wi-fi was offered at no cost to the community, in the community centre with little advertising, to determine need. Its results exceeded the expectations of the community, stakeholders, and businesses, drawing traffic and attention to the community in the summer of 2014. The timing of the project was serendipitous, coinciding with funding announcements from the Government of Canada for small community development as well as broadband and connectivity.

Keywords: Internet, rural, broadband, Wi-Fi, local economic development, connectivity

\section{Query}

There is no greater tension between the environment and the economy than that which exists in the hamlet of Honey Harbour, Muskoka. Seasonal residents make up the vast majority of the population of the hamlet and surrounding township (Muskoka Growth Strategy, 2013) and they have grown to love and adore the shorelines, the tranquility and the serenity of the community. As a group, they have declared that development is not a priority in this hamlet. Yet the 268 permanent residents of Honey Harbour (Muskoka Growth Strategy, 2013) are desperate for an opportunity to find prosperity and growth in a community where their children attend school and their families age with dignity.

With great respect for both parties, the Township of Georgian Bay reached to broadband deployment as a method for growth and service delivery in a footprint-free (ie development-free) way. However, even this choice was controversial. Seasonal residents and visitors come to Muskoka for its pristine natural environment. Perhaps by turning away from the past and working to enhance sustainable economic opportunities for Muskoka's rural communities, the region is taking away the very essence of vintage Muskoka. The bigger question becomes whether the Internet has become a service as essential as electricity, and whether this repeats the same debate that occurred when cottage communities connected to Hydro in the early 1950's? 
The District of Muskoka clearly believes that Internet is as important as electricity, and has already taken steps to provide access. In 2006, Core Broadband (the access and communications specialists serving all of Muskoka) was awarded a contract by the Muskoka Community Network, using federal funding, to install Internet towers in Muskoka ranging in size from 90 feet to over 300 feet (Muskoka Community Network, 2006). The purpose of the build was to satisfy the mandate of the Federal Government to offer a least $1 \mathrm{Mb} / \mathrm{s}$ upload and download speed to rural communities. Covering as much of the topography of Muskoka as possible - a challenge for wired Internet with the area's rock cuts, lakes, rivers, islands and valleys - Core Broadband created a backhaul system that allowed communities with limited Internet access to obtain coverage. However, the coverage was more theoretical than practical for communities further away from the towers-like Honey Harbour-as the geography described above prevented the signal from reaching many homes and cottages.

To extend and strengthen the signal, the Township of Georgian Bay installed several additional small towers and Core Broadband complimented that build and installed seven (7) modems, spanning from the Delawana Inn Resort to Honey Harbour Park (Figure 1). All of this infrastructure was temporary and was built to support a pilot project that aimed to determine the extent of demand for Wi-Fi Internet. Core Broadband installed the infrastructure at no cost to the community of Honey Harbour because it was also eager to find out if demand existed. In addition to determining demand, raw data needed to be collected to identify changes in speed as the number of users increased through the high summer season. The service would not be viable if connections slowed to a crawl during the summer.

\section{Figure 1. Coverage Area of Free Honey Harbour Wi-Fi Program ${ }^{1}$}

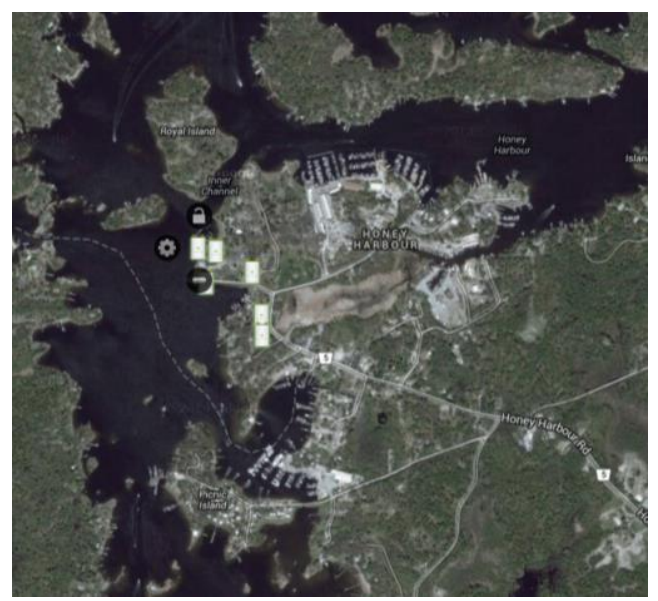

Source: Neil Smellie (2014) https://aesir.corebroadband.ca:8443/manage

\footnotetext{
${ }^{1}$ At the time of this paper, one of the seven modems was not functioning.
} 
The area covered by the HotSpot was approximately 800 feet of storefronts known as Honey Harbour Town Centre. The project was delivered from July 7, 2014, through to September 5, 2014. The purpose of the pilot time frame of this project was to collect information about usage volume (gigabit consumption), users, and user behavior (ie types of websites visited) while the seasonal and tourist populations were at their peak.

The project had limited local advertisement associated with the project to ensure that there was a strong compliment of users who came upon the Wi-Fi when entering the community. In essence, the project was not intended to draw users to the Wi-Fi, but rather to capture the natural demand for the service. By not advertising, the data was not affected by good advertising and the context of usage was created within the community by those in the community. This was essential for adding credibility to the data when discussing future funding considerations with Council.

The pilot project was devised to ensure specific usage outside of existing data plans (Rogers, Bell, Georgian Bay Public Library). The data were also being used to determine what the needs of the permanent community were.

With the question, 'Could a Wi-Fi HotSpot become an economic driver for a community with limited growth capacity?' in mind, this paper will examine:

- The demographics of Honey Harbour;

- Current internet availability;

- The results of the pilot project (including information on the extent of Wi-Fi use and user behavior);

- Considerations to support the data collected within the pilot project through funding applications where the municipality would be accountable for a portion of the total investment; and

- What the end result/need for the community would be.

Further, this paper will illustrate what happens to Internet speed/capacity when the influx of seasonal residents and tourists arrives and what considerations must be in place to provide consistent service to the permanent population, particularly those with homebased businesses. The paper will then examine the role that the Township of Georgian Bay has to play to support the provision of Internet to the communities within its geographic border, and what that delivery model might look like. The data mined from Honey Harbour could adequately transfer to the communities of MacTier and Port Severn, who also derive economic opportunities from the travelling public. This paper however will focus on the community of Honey Harbour. 


\section{Study area: Honey Harbour}

\section{Population and geography}

Honey Harbour is roughly $15 \mathrm{~km}$ to the northwest of Port Severn and is located in the Township of Georgian Bay in the District of Muskoka. Honey Harbour is the entrance to the 30,000 Islands of Georgian Bay and is a major access point for summer cottages scattered throughout the islands and coves of the Georgian Bay coastline. The population of Honey Harbour is approximately 268 permanent residents and 1152 seasonal residents (Matthew Fischer and Associates, 2014). There are almost 5 summer cottages for every year-round residence in the Honey Harbour area. Because so many of these cottages are water access only, the community is also home to dozens of marinas (Matthew Fischer and Associates, 2014). It is the only land-based community for these seasonal residents.

\section{Economy}

According to Matthew Fischer and Associates (2014) the economy of Georgian Bay is almost exclusively devoted to serving the needs of seasonal cottagers and vacationers. Unlike many communities in Ontario, there is little agriculture, resource or manufacturing employment to be found in Georgian Bay Township.

In the Township of Georgian Bay, there are no large businesses and only four businesses that have more than 50 people. Statistics Canada's Business Patterns database shows a large number of indeterminate business. Industry Canada Research shows that selfemployment is increasing at twice the rate of paid employment. The indeterminate category in Georgian Bay had a marked increase in the number of firms from 113 to 199 established between June 2011 and December 2012. Indeterminate business represents more than $50 \%$ of all business in the community. Further, $33 \%$ of all Georgian Bay businesses employs fewer than 10 employees and $25 \%$ employ fewer than five people. Georgian Bay's economy is based on serving the needs of the cottagers and the visitors. The largest employment sector in Georgian Bay is the marina industry. The majority of those Marinas are located in Honey Harbour.

Four sectors account for $77 \%$ of the total employment in Georgian Bay:

- Retail,

- Accommodation \& Food Services,

- Construction, and

- Arts, Entertainment and Recreation

Further breaking down the Retail Services sector, it was discovered that a significant portion of the Retail employment was in the subsector called "Other Motor Vehicle Dealers", which includes marinas. This is by far the largest employer group in Georgian 
Bay Township, and over $80 \%$ of the marinas are in Honey Harbour. Retail Services is the fastest growing sector in Georgian Bay largely thanks to these marinas.

Table 1 shows all sub-sectors employing more than 10 persons in Georgian Bay Township. Total employment grew by 138 jobs or $21 \%$ between 2009 and 2013 (Matthew Fischer \& Associates, 2014).

Table 1. Employment by Industry, Township of Georgian Bay, 2009-2013

\begin{tabular}{|c|c|c|c|c|c|c|}
\hline $\begin{array}{l}\text { NAICS } \\
\text { Code }\end{array}$ & Description & $\begin{array}{l}2009 \\
\text { Jobs }\end{array}$ & $\begin{array}{l}2013 \\
\text { Jobs }\end{array}$ & Change & $\begin{array}{l}\% \\
\text { Change }\end{array}$ & $\begin{array}{l}\text { Location } \\
\text { Quotient }\end{array}$ \\
\hline 4412 & Other motor vehicle dealers & 145 & 242 & 97 & $67 \%$ & 346.07 \\
\hline 7211 & Traveller accommodation & 96 & 109 & 13 & $14 \%$ & 15.90 \\
\hline 7221 & Full-service restaurants & 50 & 48 & (2) & $(4 \%)$ & 2.31 \\
\hline 4441 & Building material and supplies dealers & 34 & 42 & 8 & $24 \%$ & 6.79 \\
\hline 2361 & Residential building construction & 39 & 42 & 3 & $8 \%$ & 7.44 \\
\hline
\end{tabular}

Source: Statistics Canada (2011)

\section{Tourism and recreation assets}

The Honey Harbour area is home to a popular national park that is only accessible by water. Georgian Bay Islands National Park (GBINP), located on Beausoleil Island, is open 62 days per year. In 2013, Parks Canada had a total of 2,857 paid passengers loading the docks in Honey Harbour (Graham Lamb, personal communication, 2013). The total could be much higher if the park had more transportation capacity. The average number of travellers to the park exceeds the capacity of all available seats in Parks Canada vessels by over 140 people a day (G. Lamb, personal communication, 2013). There are no restrictions for visitors with private boats but most arrive expecting public transportation.

Over $50 \%$ of persons who visit the Georgian Bay Island National Park have been identified as part of the emerging New Canadian market. Through a marketing analysis program through the Ontario Tourism Marketing Partnership Commission that targets new Canadians and the multicultural strategic approach, access to complimentary Wi-Fi in Honey Harbour was an essential tool to assist these travellers as they navigated the National Park online system, booking opportunities and experiences in Muskoka.

Honey Harbour is perhaps best known as the location of the historic Delawana Inn, which originally opened in 1897. At its peak, the Delawana employed between 200 and 300 part-time workers, many of them students. The hotel operated continuously until 2012 when it was placed in receivership. New owners have subsequently purchased it and are restoring and redeveloping the site with perhaps some additional commercial uses. 
Honey Harbour is also the access point for two summer YMCA camps.

\section{Tensions}

There is a long history of tension between the environment and the economy in Muskoka; this is also the case in the community of Honey Harbour. The community relies on the travelling public and seasonal residents for its economic prosperity. These guests frequent this area because of their love for the environment.

The seasonal residents that visit the community of Honey Harbour have significantly higher incomes than Muskoka's permanent residents. Almost three-quarters (70\%) of seasonal residents report annual incomes over $\$ 100,000$, while only 22 per cent of Muskoka's permanent residents have similar annual incomes (Matthew Fischer and Associates (2014).

There are limited opportunities for economic growth in Honey Harbour. All properties are privately serviced and the topography makes the placement of additional septic systems difficult. However, there are numerous opportunities to better serve existing seasonal residents and derive greater benefits from the visitors coming to the National Park. The range of goods and services in Georgian Bay Township can be expected to grow in response to the growing seasonal and permanent population. Georgian Bay has been identified as a community in Muskoka with the greatest growth ratio. To be clear, while the Township of Georgian Bay has been slated to experience growth, the community of Honey Harbour is limited in its growth. The core centre will remain at its present size, with anticipated sprawl to the outlying areas of the community in the coming years. This is in part because of the opportunity for children in this community to access both a Catholic and Public School in Honey Harbour.

As more goods and services become available in the Township, there will be an opportunity to grow the proportion of purchases made at the cottage, thus increasing the economic impact of the seasonal residents' contribution to the local economy. However, at the moment there are limited goods and services available in the community of Honey Harbour, and that has had an impact on the level of pedestrian traffic in the community. Business owners have been struggling with a decline in store traffic.

\section{Internet Services in Honey Harbour}

Honey Harbour has three Internet Service Providers (ISPs). Rogers Wireless and Bell offer 4G mobile networks and the Honey Harbour library offers complimentary Internet to users who register with the library for a wireless code and use the Internet during library hours. Core Broadband's existing infrastructure is available through various ISPs for a fee to both the residential and commercial market. There were no free Wi-Fi HotSpots in the community prior to this pilot project. 
Overall, the Internet service in the community is below par, particularly for the seasonal residents. Since most of the seasonal population has a primary residence in a major urban centre, they have become accustomed to the blistering speeds and wide availability of Internet access. Permanent residents have lower expectations but still seek information that is accurate, timely and transparent through portals that are quick, consistent and frequently available. Currently, this is not available in an unlimited capacity with comparable speeds to an urban centre. The fastest upload offered in an unlimited manner is $10 \mathrm{Mb} / \mathrm{s}$ upload through broadband (N. Smellie, personal communication, July 2014).

\section{Public Internet service}

There has not been significant growth in the demand for Internet connections at the library (Table 2). To collect statistical information, library staff administers passwords for each user. There is also the fact that free internet is not advertised as a function of the library, and library hours are limited.

Table 2. Use of library internet connection in Honey Harbour, 2013 to 2014

\begin{tabular}{|l|l|l|}
\hline & $\mathbf{2 0 1 3}$ & $\mathbf{2 0 1 4}$ \\
\hline July & 195 Connections & 390 Connections \\
\hline August & 217 connections & 400 Connections \\
\hline Increase & $\mathbf{1 1 \%}$ increase & $\mathbf{3 \%}$ increase \\
\hline
\end{tabular}

Source: Barbara Swyers, CEO Georgian Bay Libraries (2014)

\section{Private Internet service}

In December 2006, broadband deployment in Honey Harbour was at $11 \%$. In December 2010, it remained at $11 \%$ (Figure 1). Bell offers limited 4G service in the Honey Harbour Area (Figure 3), while Rogers offers limited 4G service (Figure 4). Pricing for both companies is available in Table 3.

In both circumstances, the Township of Georgian Bay has fully supported application from both proponents for the dissemination of services in the community of Honey Harbour, according to the delivery models that are displayed on each individual website. 
Figure 2. Broadband Deployment in Honey Harbour, 2006-2010²

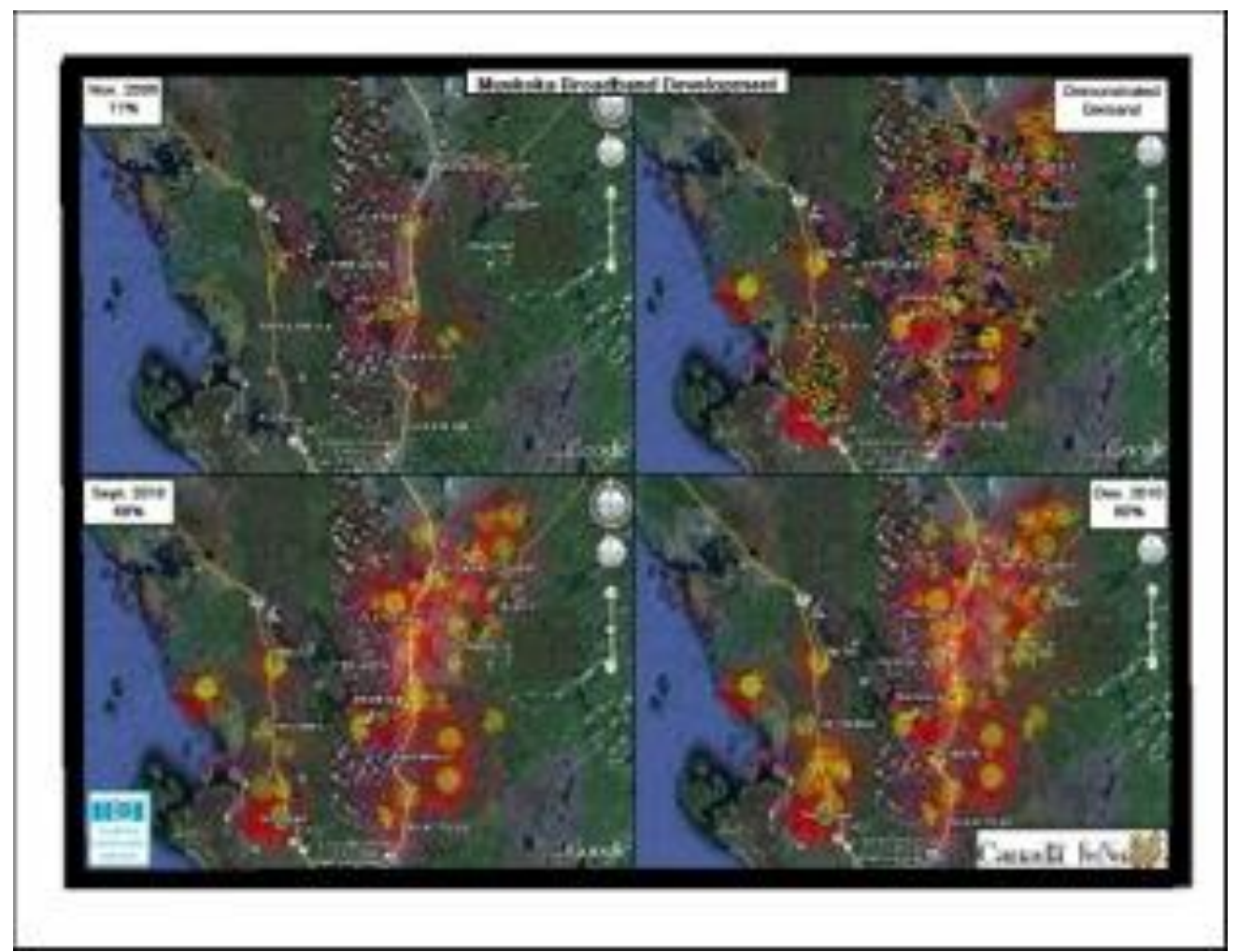

Source: Muskoka Community Network AGM, 2014

Figure 3. Proposed Coverage for Honey Harbour from Bell Canada

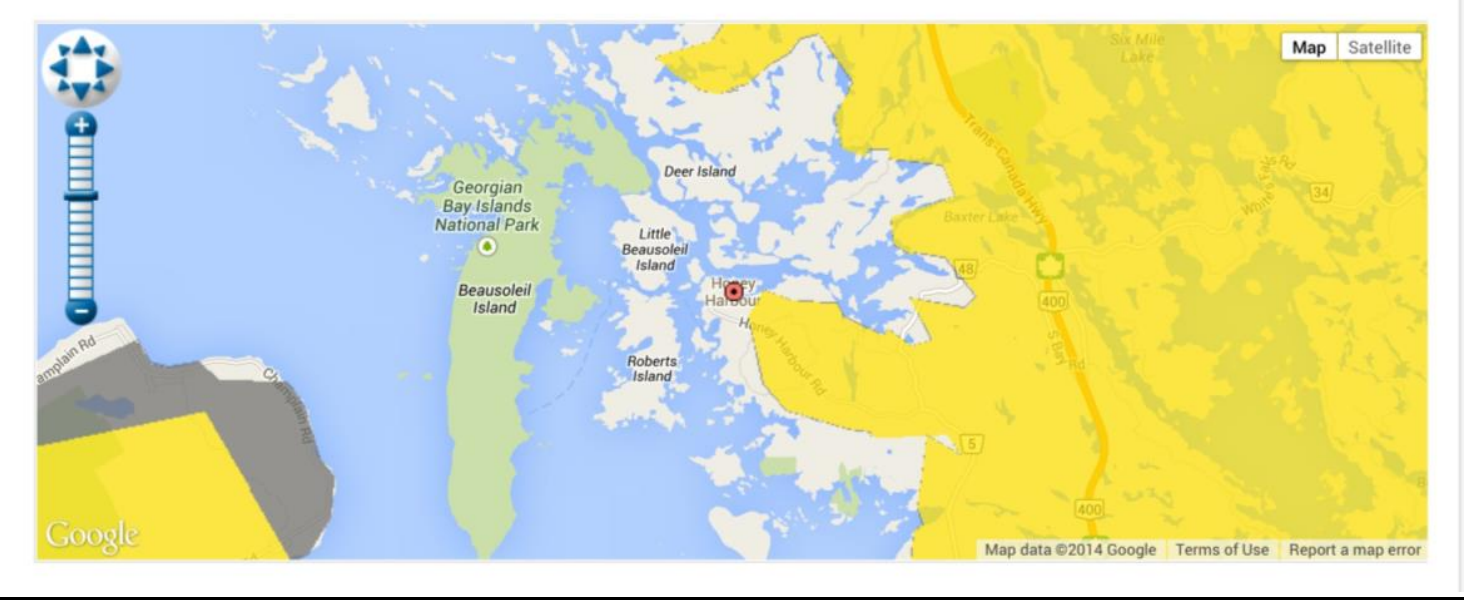

Source: www.Bell.ca

${ }^{2}$ Honey Harbour is the in the bay at the bottom left of each quadrant 


\section{Figure 4. Proposed Coverage for Honey Harbour from Rogers.}

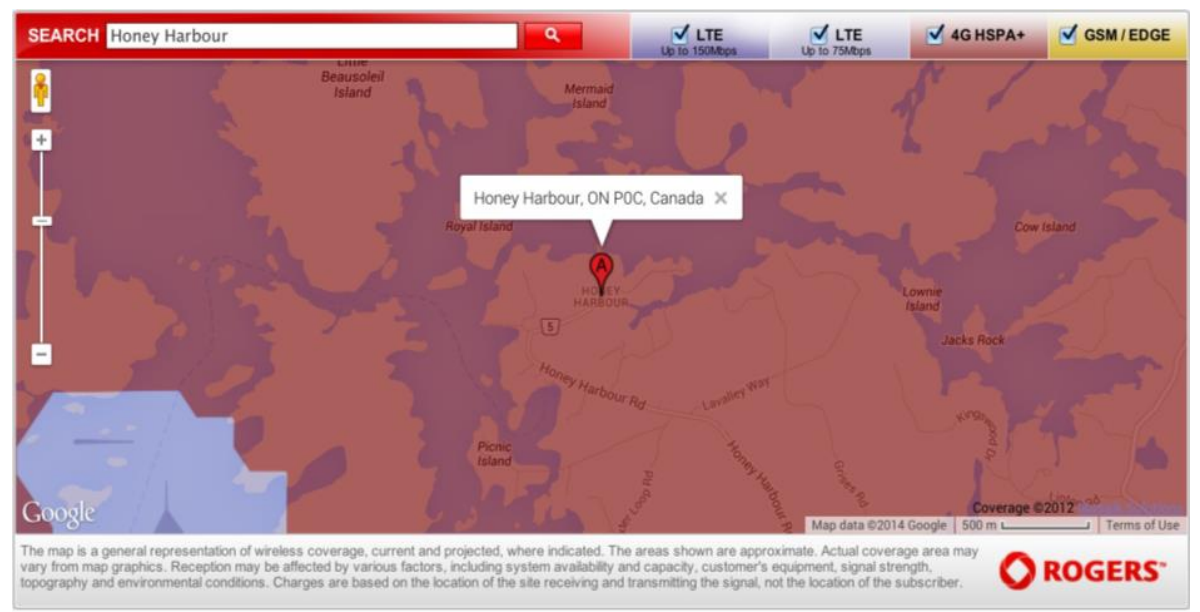

Source: www.Rogers.ca

Table 3. Gigabit data pricing for Bell and Rogers

\begin{tabular}{|l|l|l|}
\hline Service provider & Rogers & Bell \\
\hline 15 Gig & $\$ 89$ & $\$ 105$ \\
\hline Overage per gig & $\$ 15$ & $\$ 15$ \\
\hline
\end{tabular}

Source: www.bell.ca and www.rogers.ca/rates 2014

\section{Results}

The results show that the Honey Harbour Wi-Fi Pilot was very popular and exceeded the expectations of Core Broadband, despite some issues. Over the 6 weeks, only 3 of the 7 modems functioned properly through the bulk (90\%) of the time frame. Adding to this, the weather in Honey Harbour and across Central Ontario was not favourable for a significant portion of July, which decreased usage the Wi-Fi by close to $30 \%$, largely because of the inability to access the mainland and equally the lack of visitorship in the community.

Despite these issues, the findings indicate a real need in the community based on what was discovered.

\section{Extent of use}

Table 4 identifies the amount of data downloaded during the first six weeks of the pilot project. The following findings are general in nature but habitual by users over the summer.

- Over 1500 users to Honey Harbour accessed data via the unadvertised Honey Harbour Wi-Fi.

- The average session was 55 minutes in duration. 
- The highest number of visitors on a modem was 23 in one hour per modem, equally over 60 users in the community at a time.

- The weekend of August 1 to August 3, 2014 had over 300 users and 230 Gigs of data downloaded. The remarkable increase in usage was likely due to:

- Increased visitorship to the community due to events (Civic Weekend, Honey Harbour Jazz Festival),

○ The Camp Queen Elizabeth change-over from Session 1 and 2,

○ Camp Kitchikewana change-over from Session 1 and 2

- Weather of plus 24 degrees each day.

- A total of 1263 Gigs of Data were downloaded (Over 1Tb of Data)

- Approximately 230 Gigs of Data were uploaded.

- The average speed of download was $30 \mathrm{mps}$.

Table 4. Data used via free Honey Harbour HotSpot, 2014

\begin{tabular}{|l|l|l|l|}
\hline Dates & Delawana Inn & Library & $\begin{array}{l}\text { Chef House } \\
\text { (Honey Harbour } \\
\text { Road) }\end{array}$ \\
\hline July 14 & 6 Gig & 87 Gig & 100 Gigs \\
\hline July 21 & 7 Gig & 55 Gig & 107 Gigs \\
\hline July 28 & 11 Gig & 111 Gig & 87 Gigs \\
\hline Aug 3 & 11 Gig & 120 Gig & 75 Gigs \\
\hline Aug 10 & 18 Gig & 109 Gig & 100 Gigs \\
\hline Aug 17 & 15 Gig & 114 Gig & 130 Gigs \\
\hline Total & $\underline{\mathbf{6 8} \text { Gig }}$ & $\underline{\mathbf{5 9 6} \text { Gig }}$ & $\underline{\mathbf{5 9 9} \text { Gig }}$ \\
\hline
\end{tabular}

Source: N. Smellie, personal communication, 2014

User behavior

- Every user agreed to the Service Agreement without reading it (zero click through rate).

- All users uploaded and downloaded data during each session.

- Most users accessed similar sites.

- Google $-39 \%$

- Netflix $-37 \%$

○ Facebook/Twitter, Instagram, Pinterest- 19\%

- Segbay- $11 \%$

○ Remax-9\%

- Segbay, the Southeast Georgian Bay Chamber of Commerce website, was the landing page once users agreed to the service agreement. Segbay saw a significant increase in traffic in the analytics realizing over $400 \%$ increase in 
visitation to the site. Click through rates indicated that restaurants and accommodations were the most used search portal.

- Busiest activity days were Thursday to Monday.

- Users accessed Internet in the morning and after dinner habitually.

- Business owners of restaurants noticed an increased length of stay at their facilities and self-evaluated them as having a good year with the internet being in town.

- There was significant downloading that appeared to be streaming of video content. This was confirmed by the log time and data downloaded.

\section{Value of usage}

The available internet in Honey Harbour was only advertised online, and there was no signage installed in the community. Yet, if the total data downloaded were to be downloaded within contract of a carrier such as Bell or Rogers, without consideration of overage charges, the total downloaded data on the free Honey Harbour Wi-fi HotSpot was valued at $\$ 75,000-\$ 88,000$ (Table 5).

Table 5. Comparable value of gigabits downloaded in Honey Harbour during the pilot project $^{3}$

\begin{tabular}{|l|l|}
\hline Carrier & Valuation of Data \\
\hline Bell & $\$ 88,410$ \\
\hline Rogers & $\$ 74,900$ \\
\hline
\end{tabular}

Source: http://bell.ca., http://rogers.ca

Speed

Only during the installation of the backhaul (the process of connecting modems in Honey Harbour to the Wi-Fi towers), did local residents complain about a decrease in service speed, largely because of the capacity of users in Honey Harbour. This HotSpot operated independently and Core Broadband purchased separate bandwidth to operate the pilot. It is essential that residents who operate a home-based business have access to consistent speed/capacity throughout the year, and especially during the seasons where visitorship increases business potential and demand for bandwidth. Fortunately, there were no complaints during the 30 days of the trial of any capacity/speed issues.

However, speed tests during installations were as slow as $1.68 \mathrm{Mb} / \mathrm{s}$ for upload speed during installation (Figure 5a) and back to a reasonable upload speed of $6.326 \mathrm{Mb} / \mathrm{s}$ after installation (Figure 5b). This testing usually runs at $10 \mathrm{Mb} / \mathrm{s}$.

\footnotetext{
${ }^{3}$ Does not consider overage fees of $\$ 15$ per Gig after first 15 gigs
} 
Figure 5. Speed tests during installation (a) and after (b)
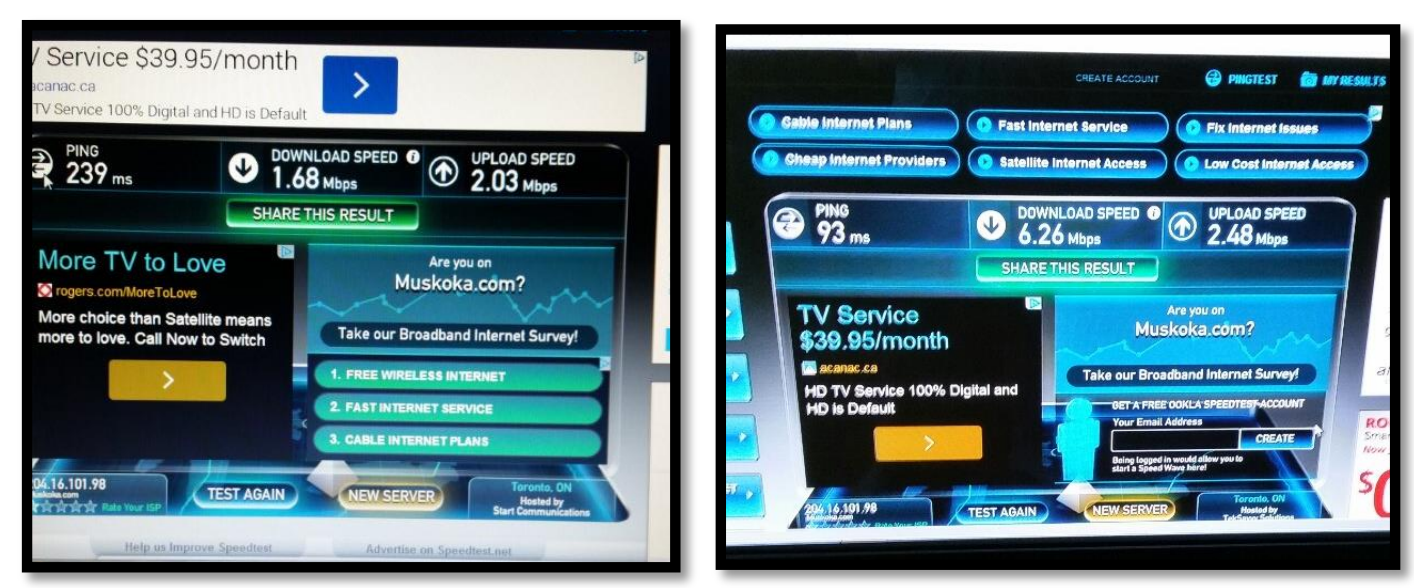

Source: Paul Herriott, Moore Point Permanent Resident (2014)

\section{Analysis}

\section{Economic Implications}

The purpose of the Wi-Fi pilot project in Honey Harbour was to determine if there is a demand for Internet. A small community such as Honey Harbour would only benefit from a Wi-Fi service if it was consistent and economic opportunities were generated. However, the conflict would then escalate and become greater, in consideration of the economic environment that is created because of the cottage community. A sustainable solution for Internet in rural communities must identify and maintain the minimum capacity and speed required for the business and stakeholder community to adequately deliver service. The influx of traffic will naturally and significantly alter the potential speed and capacity of community Wi-Fi, but the bandwidth cannot be compromised for the permanent population. This can be achieved by offering Dual Band Width of the same Broadband connector to ensure that the signal is not compromised. Permanent populations can access a different connection off the same bandwidth. (N. Smellie, personal communication, 2014)

\section{Business patronization/loyalty}

At the beginning of the pilot, staff met with business proprietors and discussed what WiFi services would be offered in the community. Given the anti-development sentiment of many seasonal residents, a footprint-free digital solution seemed to be the most appropriate way to increase sales and traffic to their business. Wi-Fi access did in fact help businesses throughout the pilot project. In addition to drawing noticeably more people into the core, businesses found that: 
1. People started to use the Internet to mark a place online in social media and on Trip Advisor,

2. Their Facebook likes increased,

3. People found previously unknown experiences to try in Honey Harbour, and

4. Honey Harbour stakeholders engaged amongst each other to support and stimulate the online conversation.

\section{Tourism development}

Wi-Fi internet made it easier for visitors to Honey Harbour to post about their experience on social media, raising the profile of Honey Harbour on sites like Trip Advisor and the internet at large. There were 10 posts during the study period on Trip Advisor (Trip Advisor, 2014)

Internet accessibility will also make the area more attractive to emerging markets and new residents of Canada. First generation Chinese Canadians enjoy luxuries when traveling and prefer to rent comfortable accommodations in a natural setting. They also list the Internet as also a top source for travel information (Ipsos Reid, 2010).

\section{Next Steps}

Identifying the geographical 'gaps' in broadband service has always been problematic, even more so now as these gaps become smaller and more isolated. ISPs need to better understand where the gaps exist, why they exist (i.e. the location is water locked), and the challenges in overcoming them.

There have been various mapping initiatives to determine the extent of the broadband 'gaps', however funding to support the completion of thorough coverage is becoming less of a priority. Now, access to speed in existing catchment areas has emerged as a higher priority. For example, in 2010, the Federal mandate from Ministry of Infrastructure and Economic Development suggested $1 \mathrm{Mb} / \mathrm{s}$ service was the standard to which ISP's would strive for. Currently that mandate has progressed to have $5 \mathrm{Mb} / \mathrm{s}$ service to become the new standard, dismissing further dissemination of services in gap or remote areas. This is largely because of the technological shift and the ease of upgrade for backhaul infrastructure using existing towers. Further, remote gap areas such as Honey Harbour are identified as 'serviced areas' with enterprises such as Bell and Rogers offering options to the consumer.

Unfortunately, at the ground level, 4G service in rural communities such as Honey Harbour is inconsistent, unpredictable and unreliable. The next identifiable solution is to enhance the infrastructure that draws broadband opportunities to communities where the backhaul exists and can be enhanced. 
It must become the responsibility of the lower tier municipalities to advocate for expanded broadband service, especially in the gap areas, and further to identify on behalf of the stakeholders where these gap areas are. This is the very essence of local economic development.

The main objective of the project was to develop data that would complement an application to FedNor, and identify the benefits that this project would bring to the community.

FedNor economic priorities are as follows:

- Improved capacity of Northern Ontario communities and businesses to address economic and business development needs and opportunities;

- increased viability, sustainability and diversification of communities in Northern Ontario;

- $\quad$ strengthened or new collaborative initiatives and strategic alliances for regional economic development among communities, regional organizations and businesses;

- increased regional capacity to access new or expanding markets through development of shared economic infrastructure;

- greater access to and adoption of services and technology by communities within a region that stimulate economic development. (FedNor, 2013)

The data collected should be sufficient to show that broadband will address development needs and opportunities and that the new infrastructure will help businesses access new markets remotely. Council's commitment to the project identifies that they are willing to engage in collaborative economic development.

Funding from FedNor is Honey Harbour's best chance to expand and permanently install the infrastructure used in the pilot, which was on loan from Core Communications.

\section{Conclusion}

The Honey Harbour Wi-Fi project did not impact the pristine environment of Muskoka. Rather, creating a virtual meeting place where people could gather to access the Internet enhanced a sense of community. Businesses noticed an increase in traffic, indicating that Georgian Bay visitors expect and desire the easy Internet access they can experience elsewhere. Public Internet access is an essential service in a community that relies on the satisfaction of the travelling public to develop economic prosperity. The community 
would be making a mistake to honour vintage Muskoka without adjusting to meet the needs of visitors.

Internet access is a basic necessity for many residents and businesses. By providing widespread Internet access on a permanent basis, the community will become more attractive to newcomers. More successful local businesses and a stronger tourism industry will add to the attractiveness.

The justification of the project, can be found within the following considerations:

1. There is the potential to attract 20,000 visitors to Honey Harbour, with a confirmed 15,000 minimum visitors per summer without any additional marketing or promotion costs.

2. One of the most visited websites in the top five (Wenxuecity) off Segbay.ca was listed by the OTMPC as a site used by New Canadians, a target market for Ontario.

3. The residents/business owners in Honey Harbour said that the streets were busier than in the past number of years.

4. Real estate sales are increasing.

5. Visual confirmation identified that there were users of the internet throughout the community (staff could see people online, and cross check with the software to confirm usage of the server).

6. There was a marginal increase of users for the library in Honey Harbour.

The role of the municipality is to engage in the process of data collection and to inform stakeholders at a grassroots level. The local economic development officer's role is to identify to Council the communities within its geographic borders that have an opportunity to increase viability, sustainability and diversification with an economic lens. When the opportunities for funding exist, the municipality must take the lead and advocate on behalf of these communities.

The Honey Harbour Wi-Fi project proved to be a feasible solution that mitigated conflict between the community's seasonal population and business owners. The ability to support a footprint-free economic opportunity does not compromise the pristine beauty of Muskoka or Honey Harbour. It does, however, encourage the growth of permanent and seasonal residents and business and stakeholders' interest in the area.

\section{Author Biography}

Jennifer Schnier is a full time employee for the Township of Georgian Bay in the District of Muskoka in the capacity of Communications and Economics Officer. Jennifer is presently enrolled part time in the Masters of Local Economic Development at the 
University of Waterloo Jennifer is married with 5 children, and lives in Muskoka. Jennifer is relentlessly advocating for increased speeds for Internet for all communities in Muskoka, but is biased to do research in Georgian Bay. Jennifer is the Vice Chair of the Muskoka Community Network, after stepping down from the position of Chair after 5 years to concentrate on her studies. Jennifer is presently in application with FedNor and Infrastructure Canada to advocate for speeds/capacity in Georgian Bay.

\section{References}

FedNor (2013). Community Economic Development. Retrieved from http://fednor.gc.ca/eic/site/fednor-fednor.nsf/eng/fn03440.html

Ipsos Reid (2010). Exploring travel motivations and attitudes of South Asians and Chinese Canadians: Qualitative Research Report. Retrieved from http://www.tourismpartners.com/research/otherReports.xhtml?language=EN

Matthew Fischer and Associates (2014). Township of Georgian Bay Community Based Economic Development Study https://georgianbay.civicweb.net/Documents/DocumentDisplay.aspx?ID=107810

Muskoka Community Network (2006, November 15). Press Release: Muskoka Community Network $(\mathrm{MCN})$ receives funding approval for the Regional Broadband Deployment Initiative. Retrieved from http://www.corebroadband.ca/PDF/broadbandfundingannouncement.pdf

Muskoka Growth Strategy (2013). District Municipality of Muskoka. https://muskoka.civicweb.net/Documents/DocumentDisplay.aspx?ID=22901

Trip Advisor (2014). Honey Harbour Canada. Retrieved from http://www.tripadvisor.ca/Tourism-g499264Honey_Harbour_Muskoka_District_Ontario-Vacations.html 